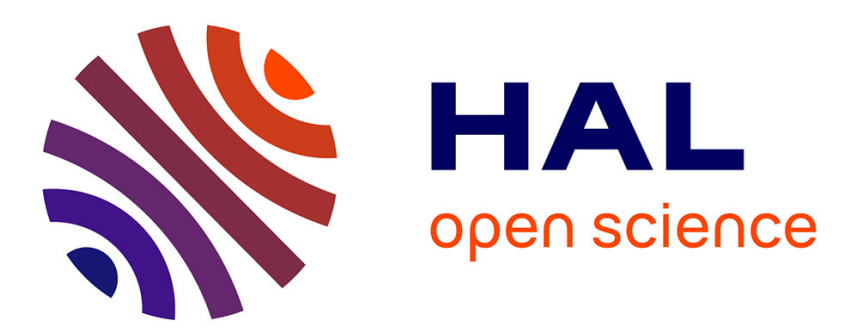

\title{
Local adaptation in European populations of Arabidopsis lyrata (Brassicaceae)
}

Païvi Leinonen, Saskia Sandring, Bénédicte Quilot, Maria J. Clauss, Thomas Mitchell-Olds, Jon Agren, Outi Savolainen

\section{To cite this version:}

Païvi Leinonen, Saskia Sandring, Bénédicte Quilot, Maria J. Clauss, Thomas Mitchell-Olds, et al.. Local adaptation in European populations of Arabidopsis lyrata (Brassicaceae). American Journal of Botany, 2009, 96 (6), pp.1129-1137. 10.3732/ajb.0800080 . hal-02668501

\section{HAL Id: hal-02668501 https://hal.inrae.fr/hal-02668501}

Submitted on 31 May 2020

HAL is a multi-disciplinary open access archive for the deposit and dissemination of scientific research documents, whether they are published or not. The documents may come from teaching and research institutions in France or abroad, or from public or private research centers.
L'archive ouverte pluridisciplinaire HAL, est destinée au dépôt et à la diffusion de documents scientifiques de niveau recherche, publiés ou non, émanant des établissements d'enseignement et de recherche français ou étrangers, des laboratoires publics ou privés. 


\title{
Local adaptation in European populations of Arabidopsis lyrata
}

\author{
(Brassicaceae) ${ }^{1}$
}

Päivi H. Leinonen ${ }^{2,7}$, Saskia Sandring ${ }^{3}$, Bénédicte Quilot ${ }^{4}$, Maria J. Clauss ${ }^{5}$, Thomas Mitchell-Olds ${ }^{6}$, Jon Ågren ${ }^{3}$, Outi Savolainen ${ }^{2}$

${ }^{2}$ Department of Biology, University of Oulu, PO Box 3000, FIN-90401 Oulu, Finland

${ }^{3}$ Plant Ecology/Department of Ecology and Evolution, Evolutionary Biology Centre, Uppsala University, Villavägen 14, SE-752 36 Uppsala, Sweden

${ }^{4}$ INRA, UR1052 Génétique et Amélioration des Fruits et Légumes F-84143 Montfavet, France

${ }^{5}$ Max Planck Institute of Chemical Ecology, 07745 Jena, Germany

${ }^{6}$ Department of Biology, Duke University, Durham, NC 27708, USA

${ }^{1}$ Manuscript received ; revision accepted

The authors thank A. Baker for the help in the early part of this study, C. Leishman, M. Hyvärinen, J. Leppälä, N. Turion, M. Andersson, A-K Roos, S. Larsson and V. Coronel for assistance in the field, and J. Oksanen for discussions on R and statistical issues. The study was financially supported by grants from the Environment and Biosciences Research Council of Finland and the University of Oulu to OS, from Formas and the Swedish Research Council to JA, and from the Swedish Royal Academy of Science and Uppsala University to SS.

${ }^{7}$ Author for correspondence (e-mail: paivi.h.leinonen@oulu.fi)

We studied local adaptation to contrasting environments using an emerging model organism of evolutionary plant biology - the outcrossing, perennial herb Arabidopsis lyrata ssp. petraea (Brassicaceae). We found variation in cumulative fitness, indicating significant adaptive differentiation among populations. Non-local populations did not exhibit higher fitness than the local population. Sites for reciprocal transplant experiments were located in Norway (alpine), Sweden (coastal) and Germany (continental). At all sites after one year, the local populations also had higher cumulative fitness, as quantified by survival combined with rosette area, than at least one of the non-local populations. At the Norwegian site, measurements were done for two additional years and fitness differences were found to persist. Fitness components contributing most to differences in cumulative fitness varied among sites. Relatively small rosette area combined with large number of inflorescences produced by German plants may reflect differentiation in life history. The results of the present study demonstrate that $A$. lyrata harbours considerable variation in several characters contributing to adaptive population differentiation. The wealth of genetic information available for this species makes $A$. lyrata a highly attractive system for examining also the functional and genetic basis of local adaptation in plants.

Keywords: Arabidopsis lyrata; Brassicaceae; local adaptation; plant establishment; population differentiation; reciprocal transplant experiment. 
Natural environments are spatially and temporally heterogeneous. This may result in differential selection across environments and evolution of local adaptation (Kawecki and Ebert, 2004; Hedrick, 2006). As a result, populations in contrasting environments evolve to differ in morphological, physiological and phenological characters. Variation in ecologically important traits often shows a clinal pattern over a latitudinal or an altitudinal gradient (e.g. Olsson and Ågren, 2002; Stinchcombe et al., 2004; Savolainen et al., 2007; Zhen and Ungerer, 2008). The conditions for evolution of local adaptation also depend on population size, being most favourable when the effective population size is large. In small populations, genetic drift and gene flow from other populations can counteract selection and thus slow down or prevent the evolution of adaptive differentiation (Wright, 1931; Holt and Gomulkiewicz, 1997; reviewed by Lenormand, 2002). Moreover, temporal variation in selection could overcome the effects of spatial variation in selection and result in one generalist genotype (Hedrick, 2006).

Reciprocal transplant experiments represent a powerful tool to detect local adaptation (Turesson 1922; Kawecki and Ebert, 2004). Such experiments provide evidence for local adaptation if the local population has the highest relative fitness at each site. In plants, reciprocal transplant experiments have demonstrated local adaptation over long distances, such as in the classical Achillea studies of Clausen, Keck and Hiesey (1948) and in provenance trial experiments of forest trees (Langlet, 1936; Eriksson et al., 1980; Wu and Ying, 2004; reviewed by Savolainen et al., 2007), but also between contrasting habitats separated by short distances as recorded in, for example, sunflowers (Sambatti and Rice, 2006). However, local adaptation has not been detected in all comparisons, indicating the potential importance of historical factors and stochastic processes for the structuring of genetic variation in characters influencing fitness (e.g. Schemske, 1984; Galloway and Fenster, 2000; Griffith et al., 2004).

Arabidopsis lyrata ssp. petraea (L.) O’Kane and Al-Shehbaz (Brassicaceae) - a close relative of Arabidopsis thaliana (Koch et al., 2000; Mitchell-Olds 2001) is an emerging model organism of evolutionary and ecological genetics. A. lyrata, in contrast to the selfing annual $A$. thaliana, is an outcrossing perennial. Both species occur in a wide range of habitats, but the distribution of A. lyrata is more disjunct. and populations are geographically isolated. Earlier studies with this species have shown that natural populations vary in many ecologically important and potentially adaptive traits. Differences have been found in flowering phenology (Riihimäki and Savolainen, 2004; Riihimäki et al., 2005;), morphology of leaves (Jonsell et al., 1995; Kärkkäinen et al., 2004; Kivimäki et al., 2007), and size and morphology of flowers (Leinonen and Savolainen, unpublished data; Sandring and Ågren, unpublished data), glucosinolate content (Heidel et al., 2006), and trichome production (Kärkkäinen et al., 2004; Kivimäki et al., 2007; Løe et al., 2007). Moreover, differences in flowering phenology between an alpine and a coastal population in northern Europe were found to be consistent with differences in current selection on flowering time (Sandring et al., 2007).

Genetic differentiation can also be seen between these phenotypically divergent populations in enzyme and microsatellite loci (Jonsell et al., 1995; Van Treuren et al., 1997; Clauss and Koch, 2006; Clauss and Mitchell-Olds 2006; Gaudeul et al., 2007; Muller et al., 2008) and in DNA sequence variation (Savolainen et al., 2000; Wright et al., 2003; RamosOnsins et al., 2004; Balañá-Alcaide et al., 2006; Wright et al., 2006). This information can help interpret the role of natural selection in giving rise to the phenotypic differentiation (Gaut and Ross-Ibarra, 2008). A. lyrata populations have also been studied for flowering time response to vernalization influenced by flowering time gene FRIGIDA (Kuittinen et al., 2008). 
A. lyrata shows geographical patterns of genetic divergence typical of many wild nonweedy plants (e.g. Olsson and Ågren, 2002, Savolainen et al., 2007). However, because fewer genetic tools are available for those species, plants such as A. lyrata (where the full genome sequence is about to be available (http://www.jgi.doe.gov/sequencing/why/3066.html), will provide exceptional opportunities for examining the genetic basis of local adaptation.

In this study, we explored evidence for local adaptation and adaptive population differentiation during early life-history stages across a wide geographic area in Arabidopsis lyrata ssp. petraea. We planted one alpine population from Norway, two seashore populations from Sweden, and a population growing on rocky outcrops and boulders in central Germany in common-garden settings at an alpine site in Norway, a coastal site in Sweden and a continental site in Germany. Locations and climatic data are presented in Table 1.

Plant fitness was recorded during the year following transplantation at all sites. Several components of fitness were measured: winter and summer survival, rosette area, flowering propensity and number of inflorescences. Specifically, we addressed the following questions: (1) is the fitness of local populations higher than that of non-local populations, and (2) which components of fitness are responsible for variation in cumulative fitness? 


\section{MATERIALS AND METHODS}

Study system-The insect-pollinated, self-incompatible, perennial herb Arabidopsis lyrata has a circumpolar distribution in the Northern hemisphere. The European subspecies ssp. petraea (syn. Arabis petraea L., syn. Cardaminopsis petraea (L.) Hiit.) has a very disjunct distribution (Jalas and Suominen, 1994; O'Kane and Al-Shehbaz, 1997). Arabidopsis lyrata grows in open habitats with little competition in alpine areas, lava fields, river sides, and sea shores, but also on rocky outcrops and on boulders in otherwise relatively closed vegetation (Schierup, 1998; Kärkkäinen et al., 1999). Plants form a leaf rosette from which inflorescences with several white or pink flowers emerge.

Design of the transplant experiment-We reciprocally transplanted populations of Arabidopsis lyrata from three contrasting environments in Europe (Table 1). The reciprocal transplant experiment included one population from an alpine habitat in Norway, Spiterstulen, two coastal lowland populations from Sweden: Storsanden and Stubbsand (about $35 \mathrm{~km}$ apart). These populations have been included in a study by Løe et al., 2007 (and were named N6, S9 and S2 respectively). We also included a population from a continental, lowland site in Plech, Germany, where plants grow on large boulders and rocky outcrops (Clauss et al., 2002; Balañá-Alcaide et al., 2006; Clauss and Mitchell-Olds, 2006).

Transplant experiments were established on a riverbank at the site of the Spiterstulen population in Norway in 2002, on seashore of the Bothnian Bay in Sweden in 2003, and in an experimental field at Dornburg near Jena in Germany (about $200 \mathrm{~km}$ from the Plech population) in 2004. It was not possible to establish our transplant experiment at the actual home site of the German population, because the plants grow in cracks of large boulders. Dornburg field site was chosen because climatic conditions are very similar to those of the site from which the Plech population originates (Table 1).

A mixture of full-sib seed families produced in controlled crosses in growth chambers and open-pollinated maternal families collected in the field (most likely representing half-sib families) were used in the experiment. At the sites in Norway and Sweden, 20 full-sib families from Plech and 20 open-pollinated maternal families from each of the Spiterstulen (collected in 2001) and Storsanden populations (collected in 1998) were sown. At the site in Germany, the Spiterstulen and the Plech populations were represented by nine full-sib families produced in controlled crosses in growth chambers. Differences in seed origin (field collected vs. crossed) was due to limitations in seed availability, and for the same reason not all families were the same among sites. Moreover, at the German site the Storsanden population was replaced by the Stubbsand population, another coastal population located about $35 \mathrm{~km}$ away from Storsanden. Because the two populations originate from the same area and similar seashore habitats (Table 1), we will consider them together as representatives of $A$. lyrata from the Swedish coast. Seeds from Stubbsand consisted of eight half-sib families collected in the field.

Transplantation-Seeds for all experimental sites were sown in $5 \times 5 \times 5 \mathrm{~cm}^{3}$ plastic pots in a mixture of unfertilized peat with sand and gravel (1:1) and the positions for the pots were randomized before germination. Sand and gravel from home sites of the populations was used for experiments in Norway and Sweden. This could not be done at the German site, because the Plech population grows on boulders. Seeds for the Norwegian and the Swedish experiments were sown near the planting sites and the pots were sheltered from wind and rain during germination. The seeds for the German experiment were sown in a greenhouse at the Botanical Gardens of the University of Oulu in Finland and transported to the site in Germany. Plants for all three sites were allowed to grow for about one month before planting. Seedlings were watered at regular intervals and no fertilizer was used. At the Norwegian and 
German sites, the plants were planted without pots. At the Swedish site however, plants were planted with pots to improve their establishment success in that particular environment. The pots were perforated allowing the relatively deep and fine roots of $A$. lyrata to grow into the surrounding soil.

The experiment included a total of 360-384 A. lyrata individuals at each site. Plants were randomized in six blocks of 60-64 individuals in Norway and Sweden, and in four blocks of 90 individuals in Germany. The distance between plants was $10 \mathrm{~cm}$ at the Norwegian and Swedish sites and $30 \mathrm{~cm}$ at the German site, where intraspecific competition was more likely to limit plant growth. Families were evenly distributed among blocks and their positions within the blocks were randomized.

The experiments were transplanted in early July 2002 in Norway, in mid-August 2003 in Sweden and at the end of October 2004 in Germany. Because A. lyrata is a pioneer species, and grows in open habitats, often without immediate competitors (Jonsell et al., 1995), competitive interactions were avoided by removing other plant species at transplantation at the Swedish and German sites. In Germany only it was necessary to keep removing competing plant species from the experimental plots. In mid-July 2002, less than two weeks after transplanting, the experimental site in Norway was temporally flooded. Individuals that died because of the flood (two Norwegian, nine Swedish and nine German plants) were replaced with other individuals from the same populations.

Measurements-The performance of experimental plants was monitored until the end of the growing season in the year following transplantation. To quantify plant size, we recorded the largest diameter of the leaf rosette and the diameter perpendicular to it for each experimental plant. We estimated the area of the leaf rosette from these measures by using the formula for an ellipse. The experimental plants were checked twice during the growing season following transplantation. In the spring, we noted whether plants had survived the winter or not. At the end of the growing season, we also recorded rosette area, reproductive status (flowered or not flowered), and number of inflorescences produced. At the Norwegian site, rosette area, reproductive status and inflorescence production by the experimental plants were recorded for one additional year, and survival for two additional years.

We estimated cumulative fitness of one-year-old plants in two ways, (a) as the rosette area at the end of the growing season (set to zero for plants that had died), and (b) as the number of inflorescences produced (set to zero for plants that had died or remained vegetative in the first year). At the Norwegian site, we also estimated the cumulative fitness of two-year-old plants, (a) as rosette area at the end of the growing season, and (b) as total number of inflorescences produced in the first two years (also set to zero in a similar way as above). Because rosette area is positively correlated with both survival and flowering propensity in A. lyrata (Løe 2006), this should be a reasonable estimate of cumulative fitness in this perennial plant. The number of inflorescences was positively correlated with the number of flowers produced (Spearman's $\rho=0.65$ for plants in the experiment in Sweden, $n=149, P<0.0001$ ), and with the number of fruits produced by flowering plants in the experiments in Norway (Spearman's $\rho=0.18, \mathrm{n}=192, P<0.01$ ) and Sweden (Spearman's $\rho=0.56, \mathrm{n}=149, P<0.0001$ ).

Relative cumulative fitness of non-local populations at each site was calculated based on each of the two cumulative fitness estimates. The mean value of each population was divided by the mean value of the local population. Selection coefficients $s$ ( $s=1$ - relative fitness), which quantify selection against the non-local genotypes, were also calculated.

Statistical analyses-To explore variation in fitness at each site, we compared the cumulative fitness and fitness components of each non-local population with that of the local population using two-way contrasts. Population and block were both defined as fixed 
variables. For the analyses, we used generalized linear models (GLM) for fitness components and linear models for analysis of cumulative fitness in the statistical package R. All statistical analyses were performed using R 2.4.1 (R Development Core Team, 2006).

We used family means for analyzing cumulative fitness. Differences in our two estimates of cumulative fitness - (a) survival combined with rosette area and (b) survival combined with the number of inflorescences, were then tested with two-way contrasts by fitting a linear model. We also examined cumulative fitness in terms of survival combined with fruit production, when this data was available (first year in Sweden and second year in Norway).

We tested for statistical significance of variation in the following fitness components: survival, rosette area, flowering propensity, and number of inflorescences. Because of mortality, all families were not represented in all blocks at the end of the experiment. Family was therefore not included as a factor in the analyses. Because of very low survival of the Swedish population at the site in Germany, contrasts were not calculated between the Swedish population and the local population for variables other than survival and rosette size at transplantation.

Survival and flowering propensity (flowering vs. non-flowering) were analysed with models assuming a binomial distribution of the residuals, and number of inflorescences with models assuming a Poisson distribution. Variation in rosette size was analysed with models assuming a Gaussian distribution of the residuals after a logarithmic transformation. To examine whether variation in winter survival could be explained by variation in rosette size, we analyzed models, which included both source population and rosette size as independent variables. We also included rosette area at transplantation as a covariate in our analysis of rosette area differences one year after transplantation.

Analyses were also done excluding plants that had been used to replace those that died because of the flood at the Norwegian site. Because results were similar, we included the replaced plants in the final analyses. 


\section{RESULTS}

Survival and size-Variation in cumulative fitness quantified as a combination of survival and rosette area at the end of the experiment provides evidence for adaptive differentiation among the three populations. Selection against non-local populations quantified by this measure was strong and differences between local and non-local populations were significant in most cases (Table 2), and with the exception of the Swedish population performing equally well in Norway and the Norwegian population performing equally well in Germany as the corresponding local populations. For the main effects of population and block in the GLM analysis, see Supplemental Data with the online version of this article.

Strongest differences in cumulative fitness in terms of survival combined with rosette area were recorded at the alpine site in Norway, where the relative fitness of the Swedish population was 0.42 and of the German population 0.34 , which corresponds to selection coefficients $(s)$ of 0.58 and 0.66 , respectively. At the coastal Swedish site, the relative fitness of the German population was $0.67(s=0.33)$, while the fitness of the Norwegian population did not differ significantly from that of the local population. Finally, at the German site, there was some selection against the Norwegian population $(s=0.37)$ although this difference was not significant (Table 2), and very strong selection against the Swedish population $(s=0.95)$.

The fitness components contributing most to differences in survival combined with rosette area of one-year-old plants varied among sites. At the Norwegian site, the local population had higher survival than the German population, and produced larger rosettes than both the German and the Swedish populations (Figs. 1a, 2d). At the Swedish site, survival by the end of the growing season did not vary among populations, but the local population produced larger rosettes than the German population (Figs. 1b, 2e). It is noteworthy that at this site, the German population had lower winter survival than the local population, but that this difference was compensated by higher summer survival (Fig. 1b, Table 3). At the German site, the local population survived better than the two non-local populations, but no statistically significant difference in rosette size was recorded by the end of the season (Figs. 1c and 2f). At the end of the experiment, very few Swedish plants were alive at the site in Germany.

At the Norwegian site, the local-population advantage in survival and rosette size observed in the first year persisted in the following two years (Figs. 1a and 3a). The difference in survival between the local and the German population grew over time, but still after three years no difference in survival was observed between the local and the Swedish population (Fig. 1a).

Among-population variation in plant size was observed already at transplantation (Figs. 2 a-c). At the Norwegian site, the local population had produced larger leaf rosettes at transplantation compared with the two non-local populations (Fig. 2d). At the Swedish site, the local population had developed larger leaf rosettes than the German population, but did not differ in this respect from the Norwegian population (Fig. 2e). At the German site, the local population had produced leaf rosettes that were larger than those of the Swedish population, but smaller than those of the Norwegian population (Fig. 2c). The significant differences persisted even when initial size was included as a covariate.

Rosette size could explain some of the variation in winter survival. A model which included rosette area as a covariate indicated that winter survival at the German site was positively correlated with rosette area $(P<0.0001)$, but also that statistically significant differences in survival among the German and Swedish population remained after the effects of rosette size were accounted for $(P<0.0001)$. No statistically significant correlation between rosette area and winter survival was detected at the other two sites $(P>0.05)$. 
Survival and inflorescence production-Our second measure of cumulative fitness describes survival combined with inflorescence production. No non-local population outperformed the local population at any site (Table 2). After one year, the German population had the high fitness in terms of number of inflorescences produced per planted seedling at all three sites, while after two years in Norway the local population outperformed the German population also in terms of this fitness measure (Table 2). At the German site, both non-local population performed more poorly, the Norwegian population having a relative fitness of $0.04(s=0.96)$ and the Swedish population $0.002(s=0.998)$. At both non-native sites, the German population slightly outperformed the local population after one year (relative fitness 1.22 in Norway and 1.16 in Sweden), but this difference was not significant (Table 2). After two years at the Norwegian site, the relative fitness of the Swedish (0.41) and the German (0.56) populations indicated superiority of the local population.

The fitness components contributing to among-population variation in number of inflorescences per planted seedling varied among sites. At the German site, the local population survived better, had a higher flowering propensity, and produced many times more inflorescences per flowering plant than the two non-local populations (Figs. 1c, 4c and 4f). After one year, the flowering propensity of the German population was significantly higher than that of the local population at the Norwegian site (Fig. 4a), while at the Swedish site no significant differences in flowering propensity were found (Fig 4b). No differences in the number of inflorescences per flowering plant were recorded among populations in Norway or Sweden (Fig. 4d and e). After two years in Norway, the lower cumulative fitness in terms of survival combined with inflorescence production of the Swedish population was due to low flowering propensity in the second year, while lower cumulative fitness of the German population with this measure was mainly because of lower survival (Figs. 1a, 3b and 3c).

In addition to the inflorescence number, we also analyzed survival in combination with the number of fruits at the Swedish site in the first year, and in Norway in the second year. In Sweden, no significant differences between populations were detected by using this fitness measure ( $P>0.05$ for both comparisons). In Norway in the second year, both non-local populations had significantly lower fitness than the local population (Norwegian and Swedish $t=4.4, P<0.0001$ and Norwegian and German $t=-2.4, P<0.05)$.

\section{DISCUSSION}

This study has documented fitness differences during early life-history stages among populations of the outcrossing, perennial herb Arabidopsis lyrata, likely in response to large scale climatic factors. Evidence of adaptive differentiation was detected in comparisons between the German population and each of the two populations from Scandinavia, while fitness differences between the alpine population from Norway and the coastal population from Sweden were weak among one-year-old plants. Variation in inflorescence production of one-year-old plants reflected differences in life-history. The results suggest that geographic variation in conditions during the establishment phase have contributed to the evolution of adaptive population differentiation in traits affecting early plant establishment in this species.

Effects of fitness components on cumulative fitness-Variation in cumulative fitness quantified as the product of survival and size of one-year-old plants demonstrated adaptive differentiation between the German population and each of the two populations from Scandinavia. Adaptive differentiation appeared as differences in both survival and vegetative size, but the relative importance of differences in these two components of fitness varied among sites. At the site in Germany, the local population survived better than the two Scandinavian populations. At both Scandinavian sites, the local population produced larger 
leaf rosettes than the German population. At the Norwegian site, survival among one-year-old plants was also higher in the local than in the German population. In other species with wide ecological amplitude, signs of local adaptation have been demonstrated and have frequently been shown to involve different fitness components in different environments (e.g. Clausen et al., 1948; Jordan, 1992; Sambatti and Rice, 2006).

Differences in survival between the German and the Scandinavian populations may reflect adaptive differences in photoperiodic responses and tolerance to cold and drought among seedlings and young plants. Clinal variation in freezing tolerance across a latitudinal gradient has been recently reported in A. thaliana (Zhen and Ungerer, 2008). In our study, the German $A$. lyrata population had lower winter survival than the local population at both the Norwegian and Swedish sites. This may be related to an inappropriate day-length response in the autumn and lower cold-tolerance in the German population when grown at high latitudes. Photoperiod pathways are involved in both timing of flowering (e.g. Stinchcombe et al., 2004) and cessation of growth in plants (Böhlenius et al., 2006). Although the importance of photoperiodic responses for vegetative growth and development of cold tolerance has not been examined in A. lyrata, the study populations are known to differ in the effects of photoperiod on flowering propensity: the Norwegian and Swedish populations require longday conditions to flower, while the German population flowers readily also under short-day conditions (Riihimäki and Savolainen, 2004). Interestingly, the German population tended to have a higher summer survival than the local population at the Swedish site, where drought stress is an important mortality factor in summer (Sandring and Ågren, personal observation). The German population, which naturally grows on rocks and boulders, seems to be quite drought tolerant (Clauss, personal observation).

In the pair-wise comparisons between the German population and the two Scandinavian populations, the local population generally had grown larger than the non-local population. At the site in Germany, there was no difference in rosette size between the local and the Norwegian population at the end of the experiment. However, because the rosette size of the Norwegian population was markedly larger at transplantation at the German site, this suggests that the local plants had grown faster during the period they were exposed to field conditions in Germany. Size at transplantation had a significant effect on rosette size after one year in Germany, but no differences between populations were found. Additional studies are needed to determine whether the environment-specific differences in vegetative size are due to among-population variation in temperature optimum for growth, competitive ability, tolerance to abiotic and biotic stress, or some other factor influencing rate of growth in A. lyrata.

The alpine population from Norway and the coastal population from Sweden showed relatively little evidence of adaptive differentiation among one-year-old plants. The local population produced larger leaf rosettes at the site in Norway, but not at the site in Sweden, and no differences in survival were recorded between the two populations at their respective home-sites. Local plants had slightly higher inflorescence production per planted seedling among one-year-old plants compared with non-locals. This may reflect similarity in selection on traits affecting plant establishment at the two sites, or alternatively, that historic factors and stochastic processes have constrained adaptive evolution. Populations of A. lyrata in Scandinavia are less genetically diverse at microsatellite loci compared with populations in central Europe (Clauss and Mitchell-Olds, 2006, Gaudeul et al., 2007, Muller et al., 2008). Further studies are required to determine whether this difference also corresponds to lower genetic diversity at loci influencing variation in quantitative traits.

Evidence for life-history evolution-A more complete understanding of adaptive differentiation among the study populations would require that later life-history stages are also considered. Among two-year-old plants grown in Norway, the flowering propensity was 
significantly higher in the local population than in the Swedish population, suggesting that adaptive differences not observed among one-year-old plants may develop at later life-history stages. However in this study, we were able to detect signs of local adaptation after only one year in this perennial species. Data gathered at the Norwegian site two and three years after transplantation of seedlings indicated that adaptive differentiation in survival and growth detected at the end of the first year persisted also into the following years. Because A. lyrata is a potentially long-lived plant, a long-term experiment would be required to cover the full life cycle. One alternative would be to transplant reciprocally not only seeds and seedlings, but also established plants (e.g., McGraw and Antonovics, 1983).

After one year, the German population had the highest inflorescence production per planted seedling at all three sites, which may reflect a fundamental difference in life history among southern and northern European populations. Previous studies conducted in experimental gardens and growth chambers also indicate that this German population has a shorter juvenile period than Scandinavian populations (Riihimäki and Savolainen, 2004; Savolainen and Ågren, unpublished data). Flowering time has been found to contribute to local adaptation, for example in Mimuls guttatus from contrasting environments (Hall and Willis, 2006).

Age at first reproduction has been shown to vary across latitudes e.g. in the perennial herb Lythrum salicaria (Olsson and Ågren, 2002). In a mild climate with a long growing season, juvenile plants may be able to acquire sufficient resources to flower in the first year without compromising survival in subsequent years. In contrast, in environments with a short growing season, plants may need several years to acquire the resources necessary for successful flower and seed production. Our results are consistent with the hypothesis that a long growing period has allowed the evolution of early reproductive maturation in some $A$. lyrata populations.

Maternal effects and the effect of the experimental design-There are some possibly confounding factors in our experimental design in terms of seed material and experimental site in Germany. Seeds that were available represented field collected seeds as well as seeds produced in growth chamber. All seeds except those from the Swedish population were from full-sib-crosses in Germany and at the other sites only the German seeds were from crosses conducted in a growth chamber. In another experiment (Leinonen et al., unpublished manuscript), we found equal rosette sizes and flowering times but slightly higher reproductive output of plants grown from seeds that have maturated in growth chamber conditions, compared with field-collected seeds. If this relationship holds true for other populations, the slight difference would not influence our conclusion in the present study. The growth-chamber-derived German plants in Germany had much better reproductive fitness that the growth chamber Norwegian plants. In Norway, in spite of the slightly conservative comparison, the growth-chamber-produced German plants did not outperform the wildcollected local population (Table 2).

Our experimental site in Germany was located about $200 \mathrm{~km}$ away from the native site of the Plech population. We used a different Swedish population in Germany than at the other two sites. Because this experiment aims to identify effects of large scale climatic factors like photoperiod and large climatic differences, we think that at this scale the use of slightly different environment or population did not have a substantial effect on our results (see Table 1 for environments).

The present study adds to previous field studies of $A$. lyrata that have also found evidence for adaptive population differentiation. Studies of phenotypic selection indicate that current selection contributes to the maintenance of genetic differentiation in flowering phenology and flower morphology among populations within the Scandinavian range 
(Sandring et al., 2007; Sandring and Ågren, unpublished data). Also, within the Swedish range, $A$. lyrata populations are more strongly differentiated with respect to trichome production, which reduces damage from insect herbivores in A. lyrata (Løe et al., 2007), than at putatively neutral marker loci (Kärkkäinen et al., 2004). Additional comparisons of population differentiation for quantitative traits and at neutral markers will add a finer scale of analysis to patterns of local adaptation of European populations of A. lyrata (Leinonen et al., unpublished manuscript).

Concluding remarks-In recent years, A. lyrata has developed into an important model system for studies of the genetics and ecology of adaptive evolution. The results of the present study demonstrate that $A$. lyrata harbours considerable amount of variation in characters that affect plant establishment and that contribute to adaptive population differentiation. Many tools developed for $A$. thaliana can be applied in further studies on ecological genetics of $A$. lyrata (Clauss and Koch, 2006). This makes A. lyrata a highly attractive system for examining the functional and genetic basis of local adaptation in plants. 


\section{LITERATURE CITED}

BALAÑÁ-ALCAIDE D., S. E. RAMOS-ONSINS, Q. BOONE, AND M. AGUADÉ. 2006. Highly structured nucleotide variation within and among Arabidopsis lyrata populations at the FAH1 and DFR gene regions. Molecular Ecology 15: 2059-2068.

BÖHLENIUS H., T. HUANG, L. CHARBONNEL-CAMPAA, A. M. BRUNNER, S. JANSSON, S. H. STRAUSS, AND O. NILSSON. 2006. CO/FT regulatory module controls timing of flowering and seasonal growth cessation in trees. Science 312: 10401043.

CLAUSEN J., D. D. KECK, AND W. M. HIESEY. 1948. Environmental responses of climatic races of Achillea. In Experimental studies on the nature of species. vol. 518, 1189. Carnegie Institute of Washington, Washington, D.C.

CLAUSS, M. J., H. COBBAN, AND T. MITCHELL-OLDS. 2002. Cross-species microsatellite markers for elucidating population genetic structure in Arabidopsis and Arabis (Brassicaceae). Molecular Ecology 11:591-601.

CLAUSS M. J. AND M. A. KOCH. 2006. Poorly known relatives of Arabidopsis thaliana. Trends in Plant Science 11: 449-459.

CLAUSS M. J. AND T. MITCHELL-OLDS. 2006. Population genetic structure of Arabidopsis lyrata in Europe. Molecular Ecology 15: 2753-2766.

ERIKSSON G., S. ANDERSSON, E. V, J. IFVER, AND A. PERSSON. 1980. Severity index and transfer effects on survival and volume production of Pinus sylvestris in northern Sweden. Studia Forestalia Suecica 156: 1-32.

GALLOWAY L. F. AND C. B. FENSTER. 2000. Population differentiation in an annual legume: Local adaptation. Evolution 54: 1173-1181.

GAUT, B. S. AND J. ROSS-IBARRA. 2008. Selection on major components of angiosperm Genomes. Science 320: 484-486.

GAUDEUL, M., H. K. STENØIEN, AND J. ÅGREN. 2007. Landscape structure, clonal propagation, and genetic diversity in Scandinavian populations of Arabidopsis lyrata (Brassicaceae). American Journal of Botany 94:1147-1155.

GRIFFITH C., E. KIM, AND K. DONOHUE. 2004. Life-history variation and adaptation in the historically mobile plant Arabidopsis thaliana (Brassicaceae) in North America. American Journal of Botany 91: 837-849.

HALL, M. C. AND J. H. WILLIS. 2006. Divergent selection on flowering time contributes to local adaptation in Mimulus guttatus populations. Evolution 60: 2466-2477.

HEDRICK P. W. 2006. Genetic polymorphism in heterogeneous environments: The age of genomics. Annual Review of Ecology, Evolution and Systematics 37: 67-93.

HEIDEL A. J., M. J. CLAUSS, J. KROYMANN, O. SAVOLAINEN, AND T. MITCHELLOLDS. 2006. Natural variation in MAM within and between populations of Arabidopsis lyrata determines glucosinolate phenotype. Genetics 173: 1629-1636.

HOLT R. D. AND R. GOMULKIEWICZ. 1997. How does immigration influence local adaptation? A reexamination of a familiar paradigm. American Naturalist 149: 563-572.

JALAS J. AND J. SUOMINEN. 1994. Atlas florae europaea. distribution of vascular plants in europe. 10. Cruciferae (Sisymbrium to Aubrieta). Helsinki University Printing House, Helsinki, Finland. 
JONSELL B., K. KUSTÅS, AND I. NORDAL. 1995. Genetic variation in Arabis petraea, a disjunct species in northern Europe. Ecography 18: 321-332.

JORDAN N. 1992. Path-analysis of local adaptation in two ecotypes of the annual plant Diodia teres Walt. (Rubiaceae). American Naturalist 140: 149-165.

KAWECKI T. J. AND D. EBERT. 2004. Conceptual issues in local adaptation. Ecology Letters 7: 1225-1241.

KIVIMÄKI M., K. KÄRKKÄINEN, M. GAUDEUL, G. LØE, AND J. ÅGREN. 2007. Gene, phenotype and function: GLABROUS1 and resistance to herbivory in natural populations of Arabidopsis lyrata. Molecular Ecology 16: 453-462.

KOCH M. A., B. HAUBOLD, AND T. MITCHELL-OLDS. 2000. Comparative evolutionary analysis of chalcone synthase and alcohol dehydrogenase loci in Arabidopsis, Arabis, and related genera (Brassicaceae). Molecular Biology and Evolution 17: 1483-1498.

KUITTINEN, H., A. NIITTYVUOPIO, P. RINNE, AND O. SAVOLAINEN (2008): Natural variation in Arabidopsis lyrata vernalization requirement conferred by a FRIGIDA indel polymorphism. Molecular Biology and Evolution 25: 319-329.

KÄRKKÄINEN K., H. KUITTINEN, R. VAN TREUREN, C. VOGL, S. OIKARINEN, AND O. SAVOLAINEN. 1999. Genetic basis of inbreeding depression in Arabis petraea. Evolution 53: 1354-1365.

KÄRKKÄINEN K., G. LØE, AND J. ÅGREN. 2004. Population structure in Arabidopsis lyrata: Evidence for divergent selection on trichome production. Evolution 58: 28312836.

LANGLET O. 1936. Studier över tallens fysiologiska variabilitet och dess samband med klimatet. Meddelanden från Statens Skogsforskningsinstitut 29: 219-286.

LENORMAND T. 2002. Gene flow and the limits to natural selection. Trends in Ecology and Evolution 17: 183-189.

LØE G. 2006. Ecology and Evolution of Resistance to Herbivory: Trichome production in Arabidopsis lyrata. Acta Universitatis Upsaliensis. Digital Comprehensive Summaries of Uppsala Dissertations from the Faculty of Science and Technology 148.32 pp. Uppsala, Sweden.

LØE G., P. TORÄNG, M. GAUDEUL, AND J. ÅGREN. 2007. Trichome production and spatiotemporal variation in herbivory in the perennial herb Arabidopsis lyrata. Oikos 116: $134-142$.

MCGRAW J. B. AND J. ANTONOVICS. 1983. Experimental ecology of Dryas octopetala ecotypes: I. Ecotypic differentiation and life-cycle stages of selection. The Journal of Ecology 71: 879-897. 142.

MITCHELL-OLDS, T. 2001. Arabidopsis thaliana and its wild relatives: a model system for ecology and evolution. Trends in Ecology and Evolution 16:693-700.

MULLER M-H, J. LEPPÄLÄ AND O. SAVOLAINEN. 2008. Genome-wide effects of postglacial colonization in Arabidopsis lyrata. Heredity 100: 47-58.

O'KANE S. L. AND I. A. AL-SHEHBAZ. 1997. A synopsis of Arabidopsis (Brassicaceae). Novon 7: 323-327. 
OLSSON K. AND J. ÅGREN. 2002. Latitudinal population differentiation in phenology, lifehistory and flower morphology in the perennial herb, Lythrum salicaria. Journal of Evolutionary Biology 15: 983-996.

R DEVELOPMENT CORE TEAM. 2006. R: A language and environment for statistical computing. Version 2.4.1. R Foundation for Statistical Computing, Vienna, Austria.

RAMOS-ONSINS, S. E., B. E. STRANGER, T. MITCHELL-OLDS AND M. AGUADÉ. 2004. Multilocus analysis of variation and speciation in the closely related species Arabidopsis halleri and A. lyrata. Genetics 166: 373-388.

RIIHIMÄKI M., R. PODOLSKY, H. KUITTINEN, H. KOELEWIJN, AND O. SAVOLAINEN. 2005. Studying genetics of adaptive variation in model organisms: flowering time variation in Arabidopsis lyrata. Genetica 123: 63-74.

RIIHIMÄKI M. and O. SAVOLAINEN. 2004. Environmental and genetic effects on flowering differences between northern and southern populations of Arabidopsis lyrata (Brassicaceae). American Journal of Botany 91: 1036-1045.

SAMBATTI J. B. M. and K. J. RICE. 2006. Local adaptation, patterns of selection, and gene flow in the Californian serpentine sunflower (Helianthus exilis). Evolution 60: 696-710.

SANDRING S., M. A. RIIHIMÄKI, O. SAVOLAINEN, AND J. ÅGREN. 2007. Selection on flowering time and floral display in an alpine and a lowland population of Arabidopsis lyrata. Journal of Evolutionary Biology 20: 558-567.

SAVOLAINEN O., C. H. LANGLEY, B. P. LAZZARO, AND H. FREVILLE. 2000. Contrasting patterns of nucleotide polymorphism at the alcohol dehydrogenase locus in the outcrossing Arabidopsis lyrata and the selfing Arabidopsis thaliana. Molecular Biology and Evolution 17: 645-655.

SAVOLAINEN O., T. PYHÄJÄRVI, AND T. KNÜRR. 2007. Gene flow and local adaptation in trees. Annual Review of Ecology, Evolution and Systematics 38: 595-619.

SCHEMSKE D. W. 1984. Population structure and local selection in Impatiens pallida (Balsaminaceae), a selfing annual. Evolution 38: 817-832.

SCHIERUP M. H. 1998. The effect of enzyme heterozygosity on growth in a strictly outcrossing species, the self-incompatible Arabis petraea (Brassicaceae). Hereditas 128: 21-31.

STINCHCOMBE, J. R., WEINIG, C., UNGERER, M., OLSEN, K. M., MAYS, C., HALLDORSDOTTIR, S. S., PURUGGANAN, M. D., AND J. SCHMITT. 2004. A latitudinal cline in flowering time in Arabidopsis thaliana modulated by the flowering time gene FRIGIDA. Proceedings of the National Academy of Sciences 101: 4712-4717.

TURESSON, G. 1922. The genotypical response of the plant species to the habitat. Hereditas 3:211-350.

VAN TREUREN R., H. KUITTINEN, K. KÄRKKÄINEN, E. BAENA-GONZALEZ, AND O. SAVOLAINEN. 1997. Evolution of microsatellites in Arabis petraea and A. lyrata, outcrossing relatives of Arabidopsis thaliana. Molecular Biology and Evolution 14: 220229.

WRIGHT S. 1931. Evolution in mendelian populations. Genetics16: 97-159.

WRIGHT S. I., B. LAUGA, AND D. CHARLESWORTH. 2003. Subdivision and haplotype structure in natural populations of Arabidopsis lyrata. Molecular Ecology 12: 1247-1263. 
WRIGHT S. I., P. FOXE, L. DEROSE-WILSON, A. KAWABE, M. LOOSELEY, B. S. GAUT, AND D. CHARLESWORTH. 2006. Testing for effects of recombination rate on nucleotide diversity in natural populations of Arabidopsis lyrata. Genetics 174: 14211430.

WU H. X. AND C. C. YING. 2004. Geographic pattern of local optimality in natural populations of lodgepole pine. Forest Ecology and Management 194: 177-198.

ZHEN, Y. AND M. C. UNGERER. 2008. Clinal variation in freezing tolerance among natural accessions of Arabidopsis thaliana. New Phytologist 177: 419-427. 
Table 1. Locations (latitude, longitude and altitude) of Arabidopsis lyrata populations and reciprocal transplant sites and climatic data (day length in the middle of growing season, mean annual precipitation $(\mathrm{mm})$ and mean annual temperature $\left(\mathrm{C}^{\circ}\right)$ ) from ten years recorded at nearby meteorological stations (Fokstua, Norwegian meteorological institute; Nürnberg near Plech and Erfurt near Dornburg, Germany's National Meteorological Service (19982007); and from Härnösand, Sweden (1996-2007).

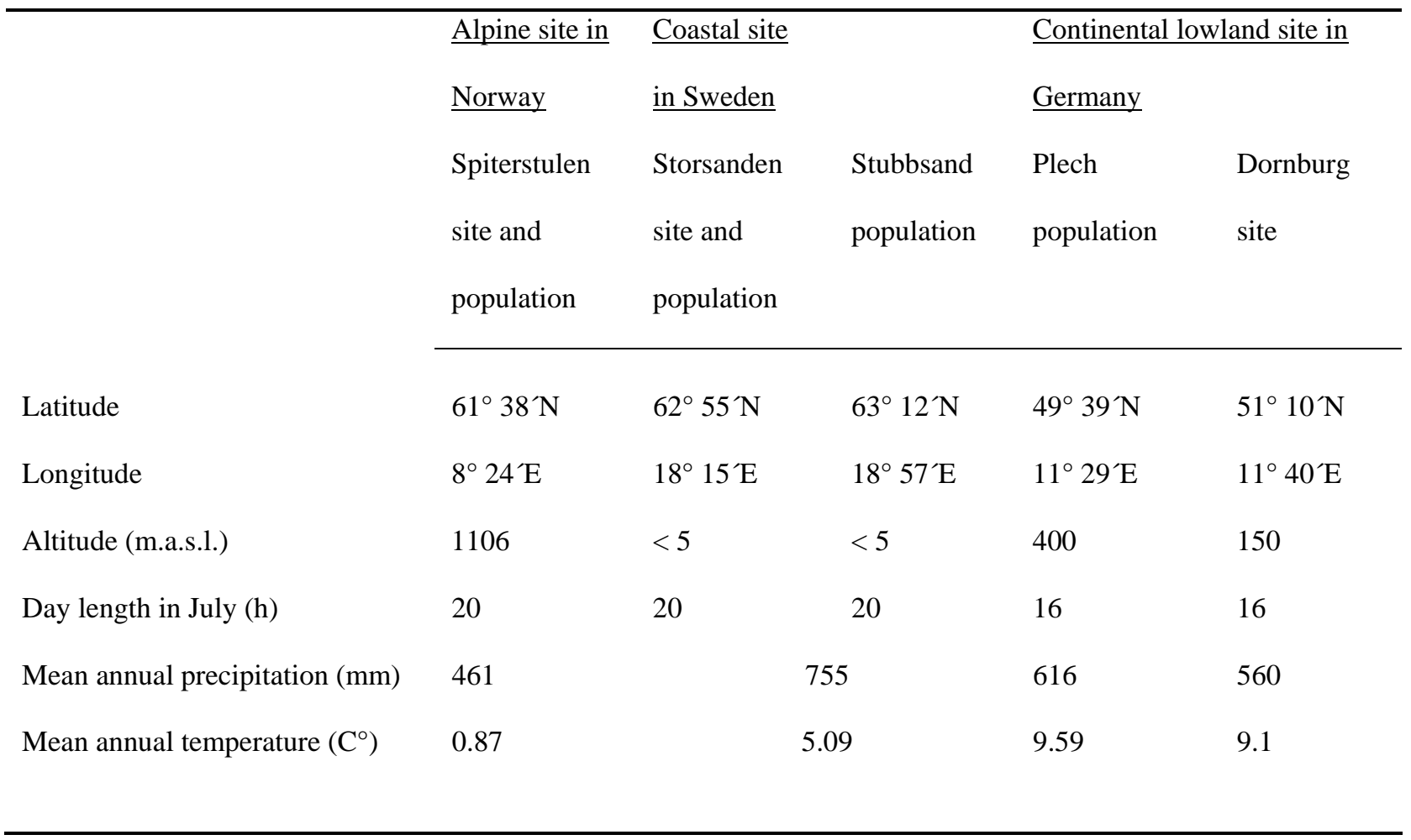


Table 2. Relative cumulative fitness of non-local populations based on survival combined with rosette area and survival combined with inflorescence production at an alpine site in Norway, a coastal site in Sweden and a continental, lowland site in Germany. Cumulative fitness values are presented in parentheses and statistically significant contrasts (based on linear models) between local (underlined) and non-local populations are indicated. Family means were used when fitting linear models. Relative fitness was calculated as mean fitness of the non-local population divided by the mean fitness of the local population. Fitness was estimated one year after transplantation at all three sites and also after two years at the Norwegian site.

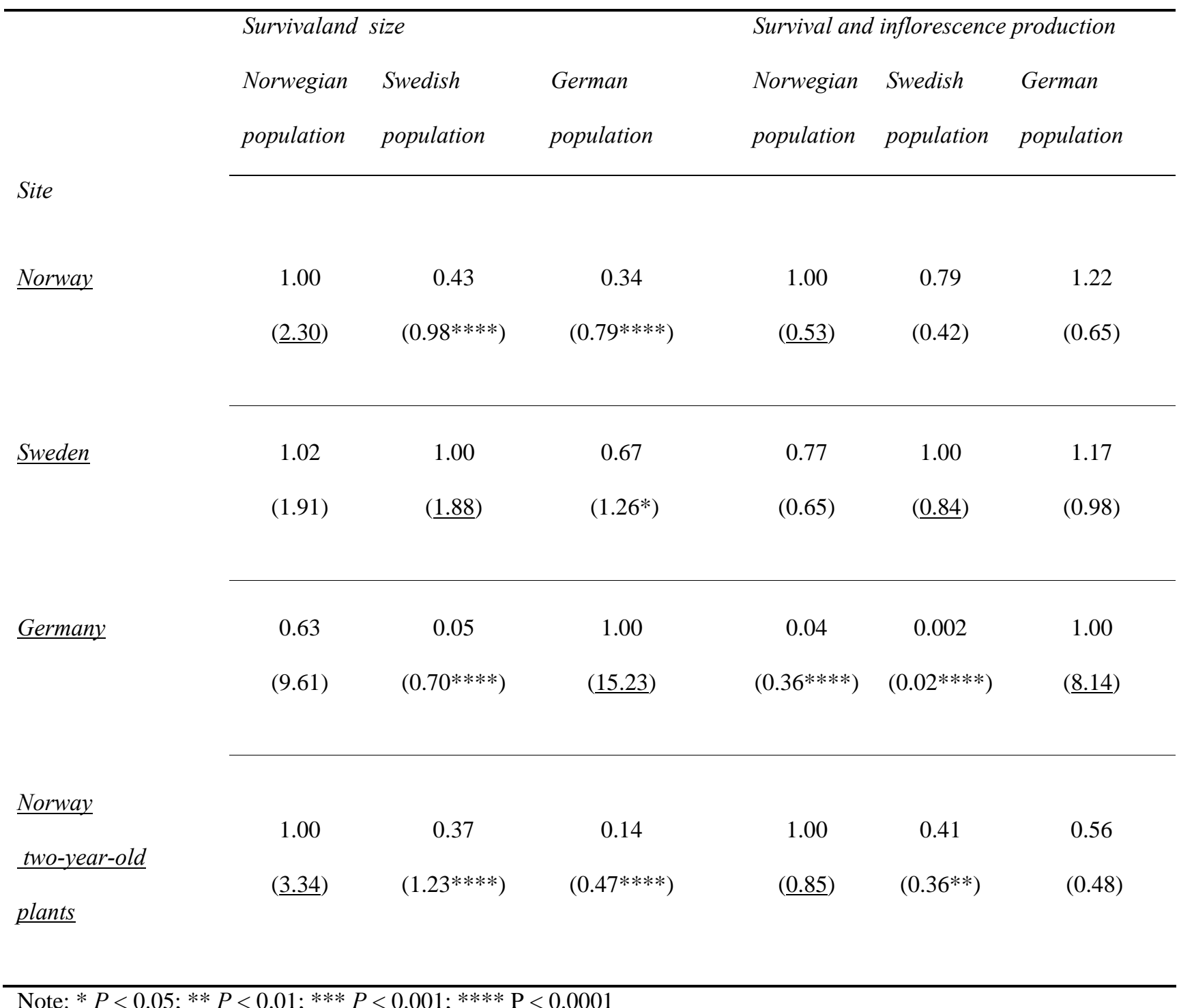


Table 3. Winter and summer survival of transplanted Arabidopsis lyrata populations at an alpine site in Norway, a coastal site in Sweden and a continental lowland site in Germany. Statistically significant contrasts (based on GLMs) between local (underlined) and non-local populations are indicated.

Winter survival $n \quad$ Summer survival $n$

$\underline{\text { Norwegian site }}$

Norwegian population

$\underline{0.98}$

120

$\underline{1.00}$

117

Swedish population

0.96

120

1.00

114

German population

$0.87 * *$

120

0.93

103

$\underline{\text { Swedish site }}$

Norwegian population

0.98

122

0.54

119

Swedish population

$\underline{0.98}$

133

$\underline{0.52}$

German population

0.92*

129

0.58

119

$\underline{\text { German site }}$

Norwegian population

0.43

120

$0.56 * * *$

52

Swedish population

$0.05 * * *$

120

0.83

6

German population

$\underline{0.53}$

120

$\underline{0.89}$

64

Norwegian site - two-year-old plants

Norwegian population

$\underline{1.00}$

117

$\underline{0.99}$

117

Swedish population

0.99

114

1.00

German population

0.82

96

0.99

79

Norwegian site-three-year-old plants

\begin{tabular}{llccc} 
Norwegian population & $\underline{0.91}$ & 116 & $\underline{1.00}$ & 106 \\
Swedish population & 0.88 & 113 & 1.00 & 100 \\
German population & $0.41^{* * * *}$ & 78 & 1.00 & 32 \\
\hline
\end{tabular}

Note: ${ }^{*} P<0.05 ; * * P<0.01$; *** $P<0.001$; **** $\mathrm{P}<0.0001$ 
A Norway
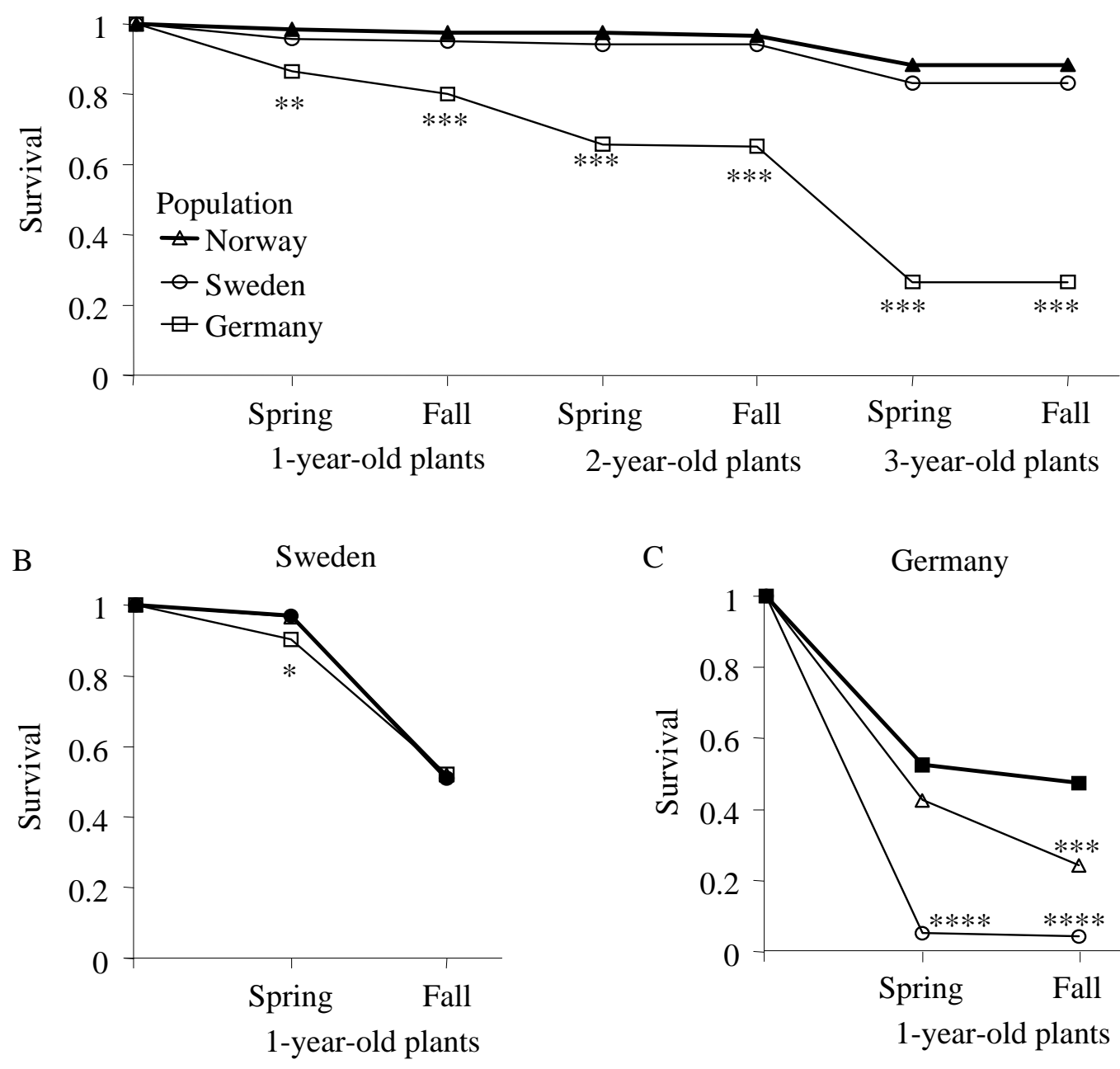

Fig. 1. Cumulative survival of three Arabidopsis lyrata populations transplanted to (a) an alpine site in Norway, (b) a coastal site in Sweden, and (c) a continental, lowland site in Germany ( $\mathrm{n}=120-135$ per population and site). Statistical significance of differences (based on GLM) in cumulative survival of one-year-old plants between local (filled symbol) and non-local populations (open symbols) is indicated. $* P<0.05$, ** $P<0.01$, *** $P<0.001$, $* * * * P<0.0001$. 

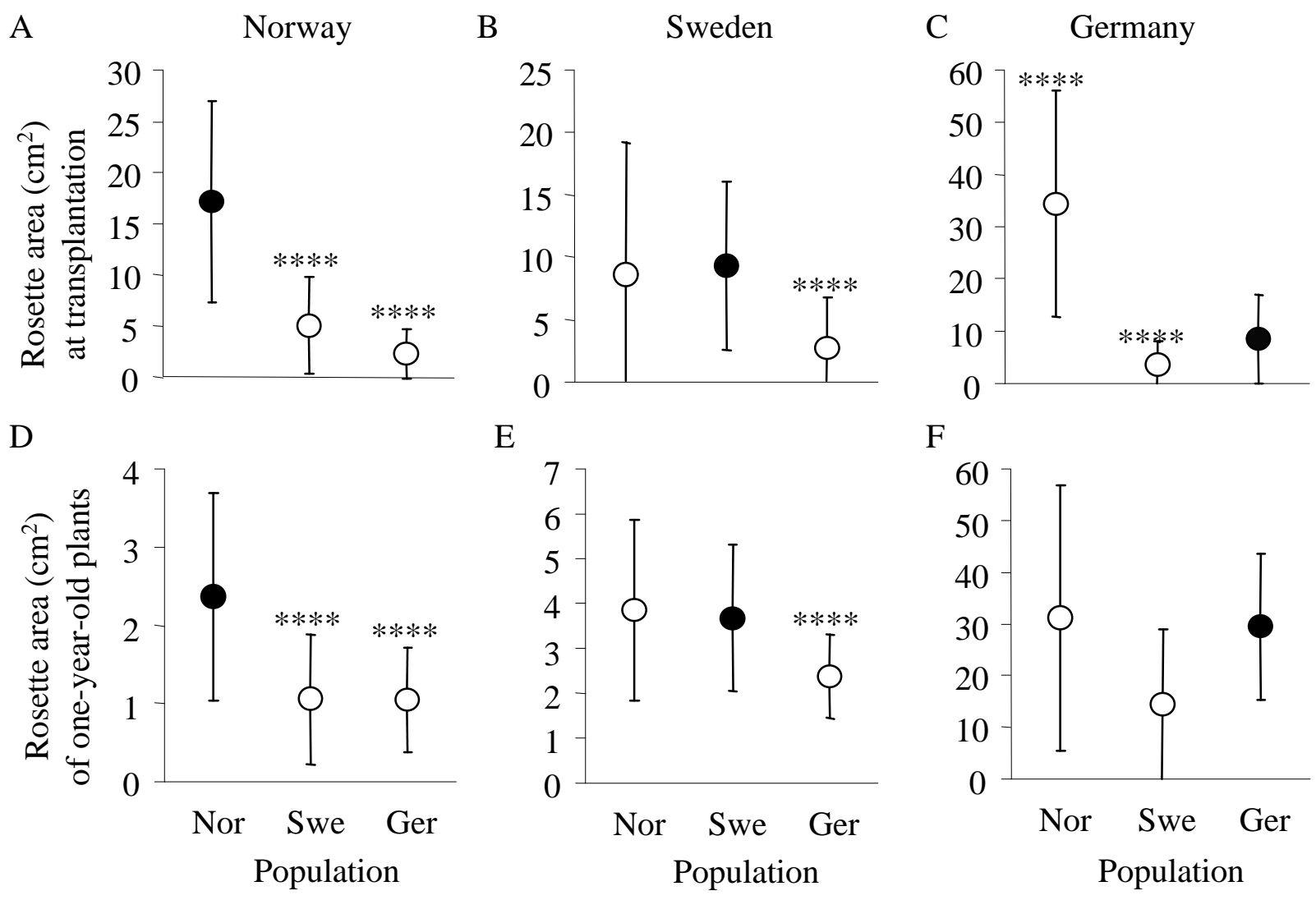

Fig. 2. Rosette area $\left(\mathrm{cm}^{2}\right.$; mean $\left.\pm \mathrm{SD}\right)$ of three Arabidopsis lyrata populations transplanted to $(a, d)$ an alpine site in Norway, (b,e) a coastal site in Sweden, and (c,f) a continental, lowland site in Germany. Rosette area $(\mathrm{a}-\mathrm{c})$ at transplantation $(\mathrm{n}=120-135)$, and $(\mathrm{d}-\mathrm{f})$ at the end of the growing season the year following transplantation $(n=37-117$, except for the Swedish population at the site in Germany $\mathrm{n}=6$ ). Note different scales on the y-axes. Statistical significance of contrasts between local (filled symbol) and non-local populations (open symbols) is indicated. ${ }^{*} P<0.05$, ** $P<0.01$, *** $P<0.001$, **** $P<0.0001$. 
A

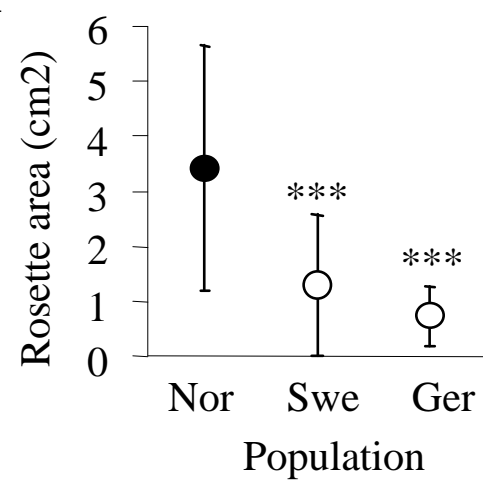

B

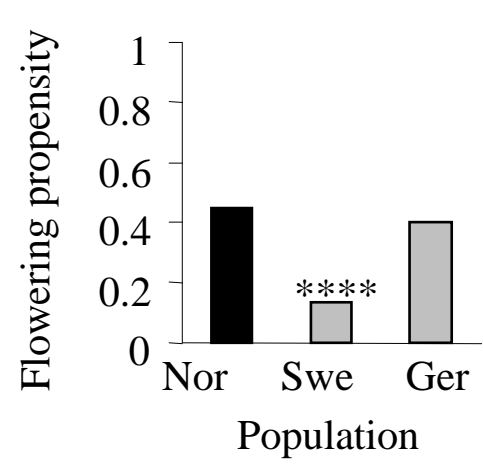

C

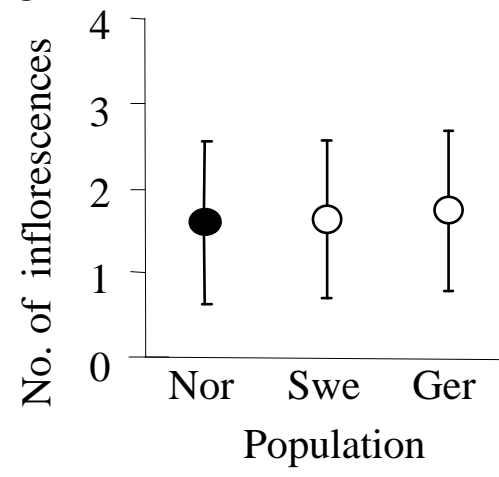

Fig. 3. Performance of three Arabidopsis lyrata populations two years after transplantation at an alpine site in Norway. (a) Rosette area at the end of the growing season $\left(\mathrm{cm}^{2}\right.$; mean $\pm \mathrm{SD}$, $\mathrm{n}=78-116)$, (b) proportion of surviving plants that flowered $(\mathrm{n}=77-116)$, and (c) number of inflorescences produced by flowering plants (mean $\pm S D, n=14-53)$. Statistical significance of contrasts between local (filled symbol) and non-local populations (open symbols) is indicated. *** $P<0.001$, **** $P<0.0001$. 


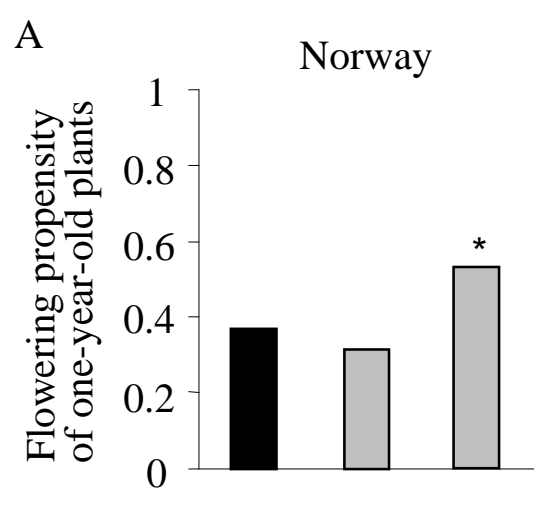

\begin{tabular}{cr|} 
B & Sweden \\
1 \\
0.8
\end{tabular}
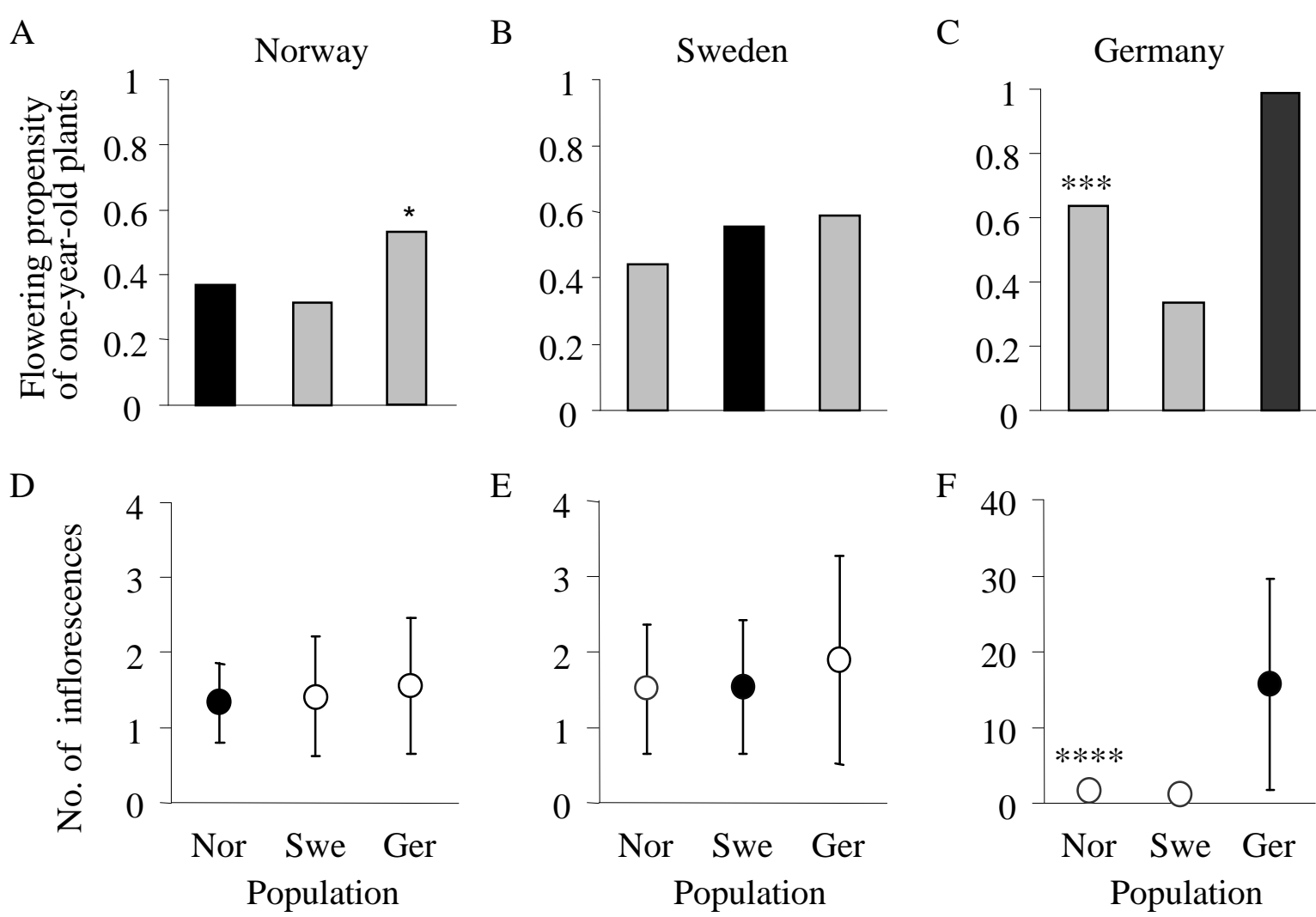

Fig. 4. Flowering in the year following transplantation of three Arabidopsis lyrata populations transplanted to (a,d) an alpine site in Norway, (b,e) a coastal site in Sweden, and (c,f) a continental, lowland site in Germany. Flowering (a-c) proportion of surviving plants ( $\mathrm{n}=52-$ 133, except for the Swedish population at the site in Germany $n=6)$, and (d-f) number of inflorescences produced by flowering plants (mean \pm SD; $n=24-74$, except for the Swedish population at the site in Germany $n=2$ ). Statistical significance of contrasts between local (filled symbol) and non-local populations (open symbols) is indicated. $* P<0.05$, *** $P<$ 0.001 , **** $P<0.0001$. 